\title{
New screening test to predict the potential impact of ivermectin-contaminated cattle dung on dung beetles
}

\author{
Jean-Pierre LUMARET ${ }^{\mathrm{a} *}$, Michel ALVINERIE ${ }^{\mathrm{b}}$, Hella HEMPEL $^{\mathrm{c}}$, \\ Hans-Joachim SCHALLNAß ${ }^{\mathrm{c}}$, Daniel CLARET ${ }^{\mathrm{a}}$, Jörg RÖMBKE ${ }^{\mathrm{c}}$ \\ ${ }^{a}$ UMR 5175 CEFE, Laboratoire de Zoogéographie, Université Montpellier 3 Paul Valéry, Route de \\ Mende, 34199 Montpellier Cedex 5, France \\ ${ }^{\mathrm{b}}$ Institut National de la Recherche Agronomique, Laboratoire de Pharmacologie-Toxicologie, \\ 180 Chemin de Tournefeuille, 31931 Toulouse Cedex, France \\ ${ }^{c}$ ECT Oekotoxikologie GmbH, Böttgerstr. 2-14, 65439 Flörsheim, Germany
}

(Received 10 November 2005; accepted 4 July 2006)

\begin{abstract}
According to European Union recommendations, a test method has been developed to evaluate the effects of veterinary pharmaceuticals on dung feeding insects. This test method was evaluated with the dung beetle Aphodius constans by using fecal residues of ivermectin after a pouron administration. Dung of different age (and thus containing different concentrations of ivermectin) as well as mixtures of highly-contaminated spiked dung with untreated control dung were studied in five test runs in two laboratories. The concentration of ivermectin (active substance; a.s.) in the dung samples was verified analytically. The main test endpoint was the survival of first instar larvae. The $\mathrm{LC}_{50}$ using dung directly obtained from treated cattle ranged from 470 to $692 \mu \mathrm{g}$ a.s. $\mathrm{kg}^{-1}$ dung (dry weight; d.w.) and 67 to $97 \mu$ g a.s. $\mathrm{kg}^{-1}$ dung (fresh weight; f.w.). Using mixtures, the outcome of two tests was almost identical: 770 to $781 \mu \mathrm{g}$ a.s. $\mathrm{kg}^{-1}$ dung (d.w.); 109 to $132 \mu \mathrm{g}$ a.s. $\mathrm{kg}^{-1}$ dung (f.w.). In comparison to the $\mathrm{LC}_{50}$ values obtained when ivermectin was spiked in control dung at several concentrations $\left(\mathrm{LC}_{50} 880-985 \mu \mathrm{g}\right.$ a.s. $\mathrm{kg}^{-1}$ dung (d.w.)), the $\mathrm{LC}_{50}$ values were again very similar. Three conclusions can be drawn from these results. The proposed test method seems to be robust and allows for the initiation of an international validation process (including ringtesting). Because of only small differences found in tests in which the test substance was spiked into control dung and those in which dung from treated cattle was applied, the use of a standard test method is proposed. The effects of ivermectin on ecologically relevant dung beetles obtained in a standardised test method reflect the results from field studies and are in the range of environmentally relevant concentrations.
\end{abstract}

environmental risk assessment / ivermectin / dung beetle / treated dung / screening test

\section{INTRODUCTION}

The development of ectocidal anthelmintics and latterly endectocides with a broad range of target pathogens has provided efficient and economic options

* Corresponding author:

jean-pierre.lumaret@univ-montp3.fr for the treatment and control of parasitic disease in both ruminants and monogastric animals. Many antiparasitic pharmaceuticals are excreted in the feces of treated animals where they can affect the survival of dung-inhabiting organisms [18]. They can also indirectly impact ecosystem functions in the field, 
particularly dung decomposition [3,16,27] Beetles of the Scarabaeidae family belong to the most important dung organisms [19]. They promote the decomposition of dung [28] in close interaction with microorganisms and other fauna like nematodes and oligochaetes, playing a vital role in maintaining pasture hygiene, nutrient cycling, soil aeration, water percolation, humus content and pasture productivity. The issue of antiparasitics (and/or their metabolites) and their environmental effects are a controversial area $[7,17,21,24,30]$, and the responsible authorities in the European Union (as well as in North America and Japan) require data on the effects of new veterinary antiparasiticals on dung organisms as part of the environmental risk assessment (see Phase II, Part A of the VICH Guidance Paper) [4,29]. Usually these data are obtained from laboratory tests (depending on their results semi-field studies are required), but up to now no standardized test guidelines are available. Therefore, the Dung Organism Toxicity Test Standardization (DOTTS) advisory group of the Society of Environmental Toxicology and Chemistry (SETAC) bringing together representatives from the industry, governmental agencies, contract laboratories and universities, decided to develop standard tests on several species, both flies and dung beetles [14]. Such a test has been developed for dung beetles within the last three years [25]. The final goal of this activity is the validation and international standardization (preferably by performing an international ringtest) of the tests according to the requirements of the Test Guideline Program of OECD [22].

Anthelmintics are of considerable value in agriculture, but possibly at an unevaluated cost to the greater environment $[10$, 30]. The determination of effect values of pharmaceuticals on non target organisms are of great interest for the industry, which needs rapid, non expensive and standardized tests. In this contribution, we present the results of tests performed with dung from treated animals at two laboratories (using very similar methodologies) and compare them with the results from tests performed with spiked dung, using the model substance ivermectin. The results also permit to validate the routine use of the dung beetle Aphodius constans in ecotoxicological tests.

\section{MATERIALS AND METHODS}

\subsection{Organisms test}

The tests were performed using young larvae (first instar) of the temperate dweller species Aphodius constans Duft. (Aphodiinae). This species was selected on the basis of its wide distribution in Europe, its long activity period and short larval development time and because it is known to have a high sensitivity to veterinary avermectins $[5,15,16]$.

Continuous breeding of this species which needs fresh dung for feeding and reproduction is difficult since this spring/winter-active beetle usually has a summer diapause. Originally, the culture was started both in Montpellier (France) and Flörsheim (Germany) using beetles of the same origin collected at a field station (Saint-Martin-de-Londres, France) located about $30 \mathrm{~km}$ north of Montpellier. Adult beetles were kept in transparent plastic boxes with a size of $42 \times 26 \times 15 \mathrm{~cm}$ while their larvae were reared in slightly smaller boxes $(27 \times 21 \times 14 \mathrm{~cm})$. The boxes were covered with gauze (mesh size: $200 \mu \mathrm{m}$ ) in order to provide a permanent air exchange. The breeding substrate at the bottom of the boxes was made of $1 / 3$ quartz sand, $1 / 3$ vermiculite (K3) and $1 / 3$ commercial garden soil with a $\mathrm{pH}$ value of about 7 (measured according to ISO 10390) [12]. The moisture of this mixture was determined according to ISO 19683, Part 4 [11]. Larval and adult boxes were kept in an 
Table I. Initial dose of ivermectin ( $\mu$ g a.s. $\mathrm{kg}^{-1}$ b.w.) administered to animals according to their weight (topical application) and ivermectin concentration ( $\mu$ g a.s. $\mathrm{kg}^{-1}$ dung (f.w.)) in fresh dung according to time after treatment.

\begin{tabular}{lccccc}
\hline & Control & \multicolumn{4}{c}{ Treated } \\
\cline { 2 - 6 } & 4 animals & Heifer 1 & Heifer 2 & Heifer 3 & Heifer 4 \\
\hline Weight of animals $(\mathrm{kg})$ & $560 \pm 25$ & 565 & 550 & 590 & 530 \\
Initial dose $\left(\mu \mathrm{g}\right.$ a.s. $\mathrm{kg}^{-1}$ b.w.) & 0 & 500 & 500 & 500 & 750 \\
\hline Time after treatment (day) & \multicolumn{4}{c}{ Ivermectin concentration $\left(\mu \mathrm{g}\right.$ a.s. $\mathrm{kg}^{-1}$} & dung) in fresh dung \\
0 & $\mathrm{ND}$ & $\mathrm{ND}$ & $\mathrm{ND}$ & $\mathrm{ND}$ & $\mathrm{ND}$ \\
1 & $\mathrm{ND}$ & 12.51 & 14.94 & 17.97 & 50.36 \\
3 & $\mathrm{ND}$ & 117.51 & 45.69 & 205.45 & 243.79 \\
12 & $\mathrm{ND}$ & 42.65 & 32.01 & 61.59 & 49.54 \\
\hline
\end{tabular}

$\mathrm{ND}=$ not detectable.

air-conditioned room $\left(18 \pm 2{ }^{\circ} \mathrm{C}\right)$ at a normal day/night schedule. Eggs and larvae remained in the dung until the latter pupated under dung pads. In order to activate the breeding period during the summer, the breeding room temperature was decreased to $4{ }^{\circ} \mathrm{C}$ for one week before returning to $18{ }^{\circ} \mathrm{C}$. Most tests were performed with larvae obtained from laboratory cultures, but some tests were also performed with larvae collected directly in the field and transferred to the laboratory in the manure of control cattle.

\subsection{Cattle}

The dung came from cattle fed mainly with grass and hay (i.e. the consistency of the dung was compact). The cattle used were two-year-old Aubrac heifers. The animals were not pregnant and had not been treated with avermectin or with an insecticide within 4 months before fecal collection. Following a ranking of the weights in descending order of magnitude, the animals were randomly allotted to blocks of four animals. The first block was treated with a topical pour-on ivermectin solution (animals numbered 1 to 4 ). The second block remained untreated and was used as the control. The average body weight (b.w.) of the treated animals was $559 \pm$
$25 \mathrm{~kg}$ (Tab. I). The animals were kept in distinct pastures under the same field conditions (Saint-Martin-de-Londres) during the entire trial period (December 2004January 2005).

\subsection{Pharmaceutical administration}

The treatment consisted of a commercial formulation of ivermectin (Ivomec ${ }^{\circledR}$ pour-on Bovins) adjusted to the individual live weight of the animals. Three animals (numbered 1 to 3 ) were treated at a dosage of $500 \mu \mathrm{g} \mathrm{kg}^{-1}$ b.w. by topical application along the back midline from tail-head to withers using a 50-mL syringe. The dosage corresponded to $1 \mathrm{~mL} 10 \mathrm{~kg}^{-1}$ b.w. The fourth heifer (number 4) received $1.5 \mathrm{~mL}$ $10 \mathrm{~kg}^{-1}$ (750 $\mathrm{g} \mathrm{kg}^{-1}$ b.w.) (Tab. I). All cattle were observed for adverse effects and for application runoff from the treated animals. Topical pour-on ivermectin is absorbed via the sebaceous glands and hair follicles. Pour-on formulation was chosen rather than oral administration of the avermectin to obtain a better comparability with literature data $[2,18,26]$. Furthermore, topical administration avoids the problems of hepatic first pass metabolism and of drug degradation in the gastrointestinal tract following oral administration, and therefore has been considered as a 
good alternative to the oral route to achieve therapeutic effects $[9,13,20]$.

\subsection{Fecal sampling}

Rectal fecal samples were collected from each of the treated and the control cattle just before treatment (on day 0), again on days 1, 3 and 12 after treatment. An aliquot of approximately $100 \mathrm{~g}$ was taken from each sample for analyses. From the total quantity of dung collected on each sampling day from each animal, $50 \mathrm{~g}$ (wet weight) was separated and kept in sealed plastic bags (date, group, animal number) for moisture content determination. All moisture content results ranged from 85 to $87 \%$ of fresh weight $(85.8 \%$ on average). Fecal material from the four control animals was mixed and homogenized and divided into five aliquots. The remaining dung of each treated animal was divided into five approximately $250 \mathrm{~g}$ subsamples for the dung beetle bioassays. Aliquots were kept separately in plastic bags, labeled, and frozen at $-20{ }^{\circ} \mathrm{C}$ until use. Part of this fecal material was used for the tests at the laboratory in Montpellier. In parallel, deep-frozen fecal material from all cattle individuals was transported to Flörsheim where it was kept under identical conditions until testing.

\subsection{Beetle bioassays}

Similar tests were performed both in Montpellier and Flörsheim, with small methodological differences in order to verify if technical changes could modify the results. However the fecal material used in both laboratories was of the same origin.

(1) Tests in Montpellier: The test vessels were six-well microplates, made of polystyrene (well volume: $5 \mathrm{~mL}$; $\varnothing 34.6 \mathrm{~mm}^{2}$ ). Five microplates were filled with the dung of each animal (treated and control). Bioassays were performed by depositing in each well one young emerged A. constans larva (1st-2nd instars). Microplates were kept in a non-transparent box (i.e. at permanent dark) in an airconditioned room at $20 \pm 2{ }^{\circ} \mathrm{C}$. The measurement endpoint was the number of surviving larvae after 3 weeks. The tests were considered valid when less than $20 \%$ of the larvae in the control plates died. Two experiments were conducted starting from the dung collected from the same animals. In the first experiment, the larval mortality was measured after 3 weeks directly using the dung which had been collected between days 0 and 12 (Tab. I). For each animal and each day, five microplates were filled with dung. In the second experiment, only the dung collected at day 3 from the animal number 4 was used, which corresponded to an initial concentration $(=100 \%$ concentration $)$ of $243.79 \mu \mathrm{g}$ a.s. $\mathrm{kg}^{-1}$ dung (f.w.) of ivermectin (Tab. I). Six successive dilutions were achieved by adding control dung to successively obtain $50 \%, 25 \%, 12.5 \%, 6.25 \%, 3.12 \%$ and $1.6 \%$, respectively, of the initial concentration, with in final $3.81 \mu \mathrm{g}$ a.s. $\mathrm{kg}^{-1}$ dung (f.w.) of ivermectin for the lowest concentration. Five microplates were filled with dung of each concentration. As in the first experiment, the mortality was measured after three weeks and in both cases the experiments were stopped at this moment.

(2) Tests in Flörsheim: The test vessels were Cellcounter tubes, made of PS/LDPE plastic (volume: $20 \mathrm{~mL}$ ). Fourteen grams fresh dung (f.w.) of treated or control dung were filled in each test vessel. Twelve tubes ( $=$ replicates) were filled with control dung and 10 tubes per treated cattle and sampling day were filled with the respective dung. Bioassays were performed by depositing in each tube one young larva (1st-2nd instars). The tubes were kept in an air-conditioned room at $20 \pm 2{ }^{\circ} \mathrm{C}$ in permanent dark. The measurement endpoint was the number of surviving 
larvae after 3 weeks. The tests were considered valid when less than $20 \%$ of the larvae in the controls died. Two experiments were conducted starting with dung collected in Montpellier from the same heifers. The first experiment consisted of two test runs in which the larval mortality in the collected dung was measured after three weeks; the tests were continued until adult emergence. In these two tests, the biomass of adult beetles hatched 8-9 weeks after starting the tests was measured in order to determine the suitability of this additional endpoint. In a second experiment, the dung collected at day 3 from heifer number 3 (Tab. I) was used in four successive dilutions. The dilution was achieved by adding control dung to dung containing the initial concentration of ivermectin. This concentration of $205.45 \mu \mathrm{g}$ a.s. $\mathrm{kg}^{-1}$ dung (f.w.) $(=100 \%)$ was diluted to $80 \%, 60 \%, 40 \%$, and $20 \%(41.09 \mu \mathrm{g}$ a.s. $\mathrm{kg}^{-1}$ dung (f.w.)), respectively.

\subsection{Analytical methods}

Ivermectin was determined by high performance liquid chromatography (HPLC) with automated solid phase extraction and fluorescence detection by the method previously described [1]. The analytical method used to extract, derive and quantify the fecal concentration of ivermectin was adequately validated. The mean extraction recovery was $72.4 \pm 9.3 \%$. The inter assay precision showed a variation coefficient of $9.0 \%$. The limit of quantification was $10 \mu \mathrm{g} \mathrm{kg}^{-1}$. Besides the initial concentrations in the dung of the four heifers at three different dates (Tab. I), the concentrations of selected samples of experiment No. 2 performed in Flörsheim (i.e. the successive dilutions of the dung collected three days after treatment from heifer number 3 ) were measured (Tab. II). All determinations were done in five replicates. Due to the small differences between the nominal and measured concentrations, no adjust-
Table II. Concentrations of ivermectin in three mixture ratios (5 replicates) using dung collected on day 3 from the treated heifer number 3 (in $\mu$ g a.s. $\mathrm{kg}^{-1}$ dung (f.w.)).

Nominal $205.45(100 \%) 123.3(60 \%) 41.1(20 \%)$

\begin{tabular}{llll}
\hline Measured & $242.0 \pm 8.4$ & $122.5 \pm 5.0$ & $50.0 \pm 0.0$
\end{tabular}

ment of the ivermectin concentrations was done when calculating the lethal concentration $50\left(\mathrm{LC}_{50}\right)$ values.

\subsection{Data assessment}

Larval mortality after 3 weeks was compared between the treated and untreated groups, and among treated groups. The nonparametric Fisher Exact Binominal test was used for comparison between the samples of treated and untreated dung $(P \leq$ 0.05 , one-sided). For the calculation of the $\mathrm{LC}_{50}$ values (larval mortality), probit analysis using linear maximum likelihood regression was performed [6]. All data analyses were performed using the Minitab $^{\circledR}$ Version 13 statistical package (Montpellier, France) and ToxRat (Flörsheim, Germany).

\section{RESULTS}

The concentrations of ivermectin in cattle dung following a topical administration of ivermectin to animals are indicated in Table I. Ivermectin was detected in dung as of the first day following the treatment and high concentration levels were still observed at day 12 post-treatment. These samples were used in experiments, both in Montpellier and Flörsheim.

(1) Montpellier: In the first experiment in which the larval mortality was measured directly using the collected dung, the $\mathrm{LC}_{50}$ value was $67 \mu \mathrm{g} \mathrm{kg} \mathrm{kg}^{-1}$ dung (f.w.), which corresponds to $470 \mu \mathrm{g}$ a.s. $\mathrm{kg}^{-1}$ dung (d.w.). In Figure 1 the percentage of 


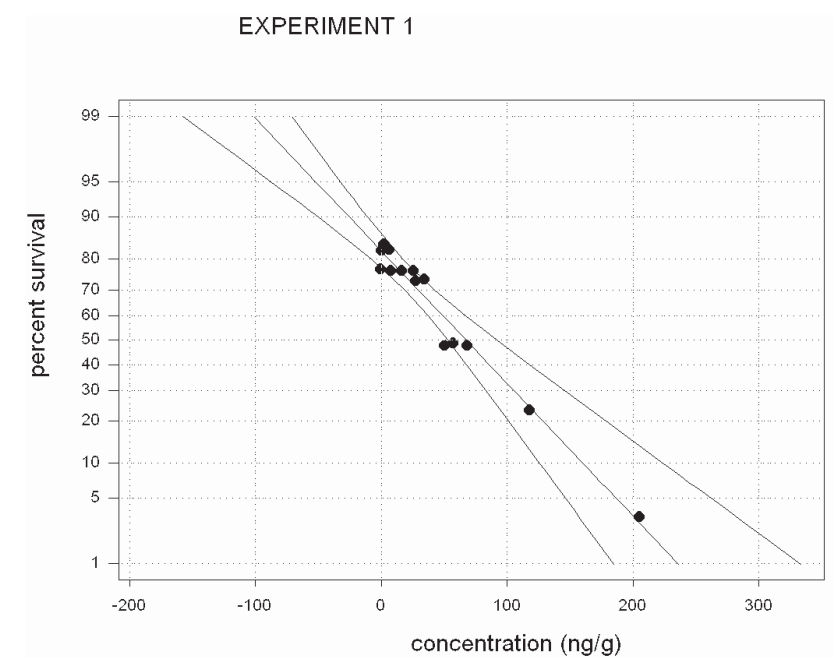

Figure 1. Percentage of surviving larvae according to ivermectin concentration $\left(\mu \mathrm{g} \mathrm{kg}^{-1}\right)$ in the fresh dung (experiment 1, Montpellier).

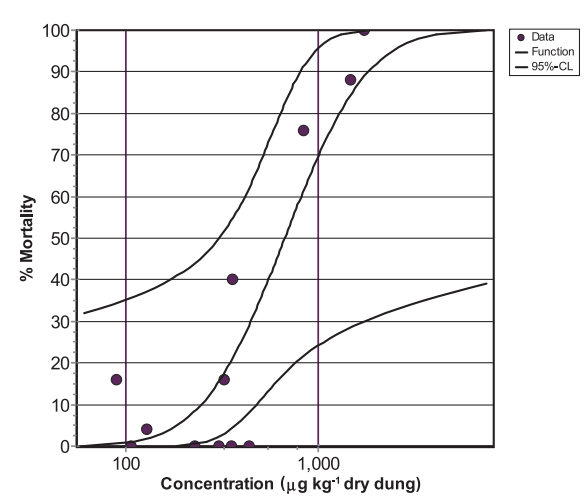

Figure 2. Dose-response curve with $95 \%$ confidence limits (CL) based on larval mortality in dung obtained from cattle treated with ivermectin (mg a.s. $\mathrm{kg}^{-1}$ dung (d.w.)) (experiment 1, run 1; Flörsheim).

surviving larvae according to ivermectin concentration in fresh dung is shown. In the second experiment, using the successively diluted dung of animal number 4 , the $\mathrm{LC}_{50}$ value was $109 \mu \mathrm{g}$ a.s. $\mathrm{kg}^{-1}$ dung f.w.) (i.e. $770 \mu$ g a.s. $\mathrm{kg}^{-1}$ dung d.w.). The $\mathrm{LC}_{50}$ values obtained in the two experiments were not significantly different $(t=$ $-1.26 ; P=0.219$; df $=25$ ).

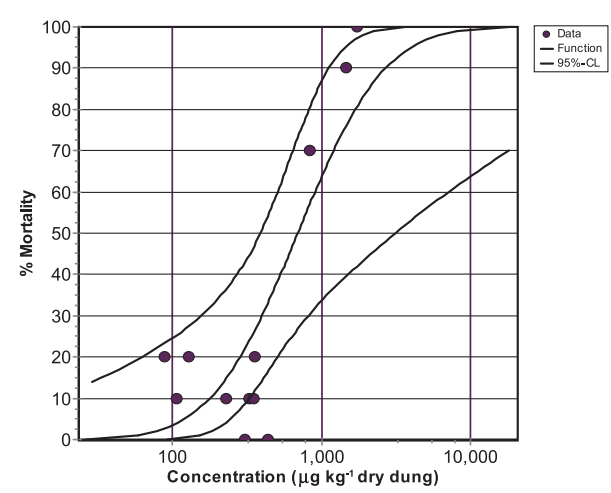

Figure 3. Dose-response curve with $95 \%$ confidence limits (CL) based on larval mortality in dung obtained from cattle treated with ivermectin (mg a.s. $\mathrm{kg}^{-1}$ dung (d.w.)) (experiment 1, run 2; Flörsheim).

(2) Flörsheim: In the two runs of the first experiment, in which the larval mortality was measured directly using the same dung collected in Montpellier but with another vessel protocol, the $\mathrm{LC}_{50}$ values were 94 and $97 \mu \mathrm{g}$ a.s. $\mathrm{kg}^{-1}$ dung f.w., respectively (= 670 and $692 \mu \mathrm{g}$ a.s. $\mathrm{kg}^{-1}$ dung d.w.). Figures 2 and 3 show the dose-response curves with $95 \%$ confidence 


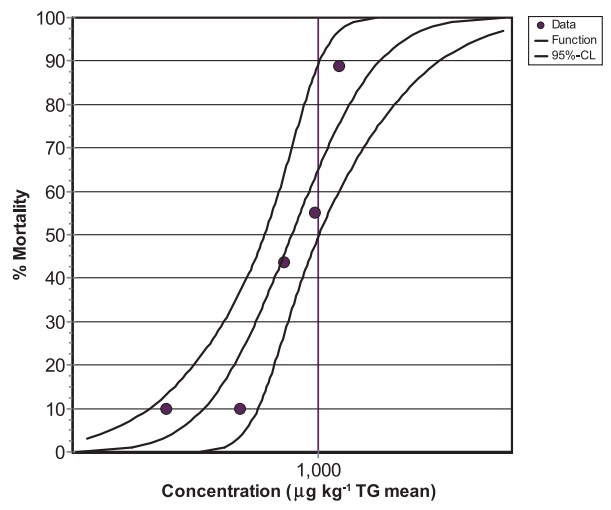

Figure 4. Dose-response curve with $95 \%$ confidence limits (CL) based on larval mortality in dung obtained from cattle treated with ivermectin (mg a.s. $\mathrm{kg}^{-1}$ dung (d.w.)) (experiment 2, run 1; Flörsheim).

limits (CL) based on larval mortality in dung obtained from cattle treated with ivermectin. In the second experiment using dung collected at day 3 from animal number 3 (initial ivermectin concentration: $205.45 \mu \mathrm{g}$ a.s. $\mathrm{kg}^{-1}$ dung f.w. and successively diluted), the $\mathrm{LC}_{50}$ value was $132 \mu \mathrm{g}$ a.s. $\mathrm{kg}^{-1}$ dung f.w. $\left(=781 \mu \mathrm{g}\right.$ a.s. $\mathrm{kg}^{-1}$ dung d.w.) (Fig. 4). Neither the number of adults nor their biomass (8-9 weeks after starting the two test runs of experiment 1) did reveal new information (Fig. 5). In fact, nearly all larvae counted after three weeks hatched and survived until the final assessment (data not shown). Due to the variable number of surviving adult beetles per concentration and the lack of a dose-responserelationship, no statistical evaluation was done.

\section{DISCUSSION}

From a methodological point of view, the proposed test method using first instar larvae of Aphodius constans is quite robust in terms of small technical changes, e.g. different test vessel (microwell plates or plastic tubes) changes. While the survival of larvae (determined after three weeks) proved to be a sensitive endpoint, the measurement of survival and biomass of adult beetles eight to nine weeks after starting the tests did not reveal new information. In addition, the results are very similar independently whether the tests were performed in Flörsheim or Montpellier. Finally, the small differences in the $\mathrm{LC}_{50}$ values gained in tests with dung directly from treated cattle or with mixtures between treated and control dung confirm the applicability of the new test method. Despite the small data base, it seems that a standard test in which the test substance is spiked into control dung is a suitable tier 1 test method.

The $\mathrm{LC}_{50}$ values of the two experiments were not significantly different, with a final $\mathrm{LC}_{50}$ value of $590 \mu \mathrm{g}$ a.s. $\mathrm{kg}^{-1}$ dung (d.w.) when all data were pooled. This final $\mathrm{LC}_{50}$ value was of the same order of magnitude as those obtained by Hempel et al. [8] ( $\mathrm{LC}_{50}$ 880-980 $\mu$ g a.s. $\mathrm{kg}^{-1}$ dung (d.w.)) when ivermectin was spiked in dung, both using fresh dung as well as dried, grounded and re-wetted dung as the test substrate. Hempel et al. [8] showed that the ratio of NOEC (No-Observed Effect Concentration) / LOEC (No-Observed Effect Level)-values for spiked ivermectin ranged from 320 to 800 for dried dung to 310 780 for fresh dung (in $\mu$ g a.s. $\mathrm{kg}^{-1}$ dung (d.w.)). When considering the concentration of ivermectin in dung collected one day after the topical administration to animals (only for heifers No. 1, 2 and 3 which received a treatment of $500 \mu \mathrm{g} \mathrm{kg}^{-1}$ body weight) (Tab. I), the concentration in dung ranged from 90 to $130 \mu$ g a.s. $\mathrm{kg}^{-1}$ (d.w.) and was lower than the NOEC determined by Hempel et al. [8]. At day 3, the values ranged from 830 to $1450 \mu \mathrm{g}$ a.s. $\mathrm{kg}^{-1}$ (d.w.) and were higher than the effect values of the tests performed by Hempel et al. [8] $\left(\mathrm{LC}_{50}\right.$, NOEC and LOEC) and obtained in the present work $\left(\mathrm{LC}_{50}\right)$. At day 12 , the 


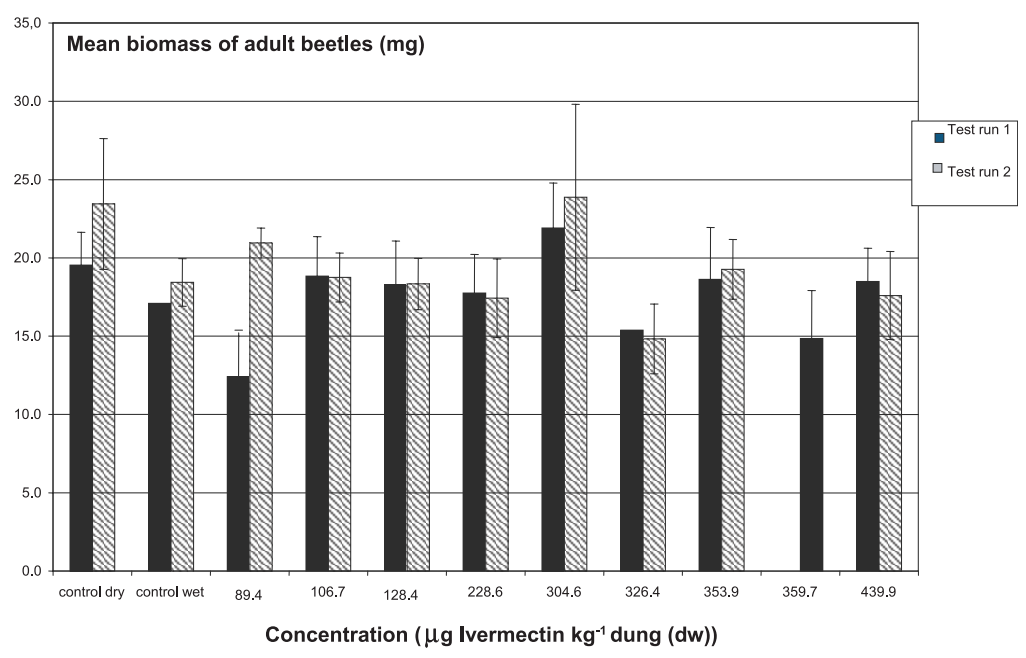

Figure 5. Mean biomass of adult beetles according to the ivermectin concentration ( $\mu \mathrm{g}$ a.s. $\mathrm{kg}^{-1}$ dung (d.w.) in experiment 1, run [1 + 2]; Flörsheim (8-9 weeks after start of the test).

concentration values (300-430 $\mu \mathrm{g}$ a.s. $\mathrm{kg}^{-1}$ dung (d.w.)) were close to NOEC but lower than the $\mathrm{LC}_{50}$ values. Thus, the results of the tests with spiked ivermectin and those using dung from ivermectin-treated cattle were in good agreement.

Our results provide evidence that a topical application of ivermectin (Ivomec ${ }^{\circledR}$ Pour-on Bovins) at a dosage of $500 \mu \mathrm{g} \mathrm{kg}^{-1}$ b.w. can significantly affect survival of dung beetles, with no significant adverse effect for larvae after twelve days posttreatment. Similar results were obtained after application of $500 \mu \mathrm{g} \mathrm{kg}^{-1}$ b.w. of heifers in a Danish field study. The number of beetle larvae (Aphodius spp.) were significantly reduced in dung pads 1-2 days after excretion while there was no effect starting on days 13/14 [26]. These results were also similar with those obtained in independent experiments in which ivermectin was applied as a sustained-release bolus [5]. In one trial, the concentration of ivermectin 135 days after treatment (i.e. $192 \mu \mathrm{g}$ a.s. $\mathrm{kg}^{-1}$ dung d.w., corresponding to $38.4 \mu \mathrm{g}$ a.s. $\mathrm{kg}^{-1}$ dung f.w.) caused a significant decrease of the rate of emergence of $A$. constans compared to the control. In the other trial, the long-term application of ivermectin (147 days after treatment at a concentration of $7.2 \mu \mathrm{g}$ a.s. $\mathrm{kg}^{-1}$ dung f.w. $=36 \mu$ g a.s. $\mathrm{kg}^{-1}$ dung d.w.), did not allow the emergence of beetles for a period of up to 128 days after administration of the sustained-release bolus to the steers.

Some authors have provided evidence that when administered as pour-on formulation to cattle, ivermectin concentration could exceed $200 \mu \mathrm{g} \mathrm{kg}^{-1}$ in fresh dung (1.400 $\mu$ g a.s. $\mathrm{kg}^{-1}$ dung d.w.) during five days post-treatment, and $100 \mu \mathrm{g} \mathrm{kg}^{-1}$ fresh dung until day 9 [2]. The concentrations after 9 days exceeded $\mathrm{LC}_{50}$ values obtained by Hempel et al. [8] for ivermectin. Thus, they could adversely affect dung beetles. It has been demonstrated that ivermectin and the structurally related compounds doramectin and moxidectin could be exchanged as a result of licking between animals kept together in the same pasture [2]. The presence of unexpected high residue concentrations of doramectin, ivermectin and moxidectin in untreated animals which had access to treated 
heifers (transfer by allo-licking with fecal excretion of some treated cows which attained levels observed in treated ones) suggests an excessive burdening in the environment. However, such non-target effects on dung organisms could easily be minimized by avoiding pasturing of animals on meadows during the first ten days after medication.

We concentrated our work on the performance of the laboratory test with beetles, and further research is needed to propose an optimal final design. When having gained more test results, we can give recommendations based on the power of the tests. It was not the aim of this paper to decide whether this study has to be adopted as a more general screening approach. However, we consider this test with dung beetles as applicable for different veterinary drugs [8]. For other dung organisms (e.g. dung flies), of course specific test methods are needed [23]. The next step in the development of this test is the formal standardization by OECD, for example as a test guideline or as a guidance document. According to the current legal situation (VICH 2005) [24], the test - together with a dung fly test [23] - is required for all antiparasitic pharmaceuticals which are used to treat pasture animals (Tier A, Chapter 3.1.3.2). According to the VICH guideline as well as to the recently published Technical Guidance Document [4] further tests are necessary if an environmental risk is identified in the dung beetle test. Up to now, no details have been fixed for this Tier B level, but either a semifield or a field study (probably including a study on the decomposition of dung) would be possible. In case that such a Tier B test still indicates concern, the use pattern of this substance (e.g. concerning the frequency of application) or its exposure in the environment (e.g. by keeping the treated animals in-house for about ten days after application) could be changed accordingly.

\section{ACKNOWLEDGEMENTS}

The work was supported by the German Federal Environmental Agency (Project No. 202 67 428). We thank P. Teisserenc who supplied cattle, G. Niogret and J.F. Sutra for technical assistance, and the two anonymous referees for their very useful comments.

\section{REFERENCES}

[1] Alvinerie M., Sutra J.F., Galtier P., Lifschitz A., Virkel G., Sallovitz J., Lanusse C., Persistence of ivermectin in plasma and faeces following administration of a sustainedrelease bolus to cattle, Res. Vet. Sci. (1999) 66:57-61.

[2] Bousquet-Mélou A., Mercadier S., Alvinerie M., Toutain P.L., Endectocide exchanges between grazing cattle after pour-on administration of doramectin, ivermectin and moxidectin, Int. J. Parasitol. (2004) 34:12991307.

[3] Edwards C.A., Atiyeh R.M., Römbke J., Environmental Impact of Avermectins, Rev. Environ. Contam. Toxicol. (2001) 171:111137.

[4] EMEA, Guideline on environmental impact assessment for veterinary medicinal products in support of the VICH guidelines GL6 and GL38, EMEA/CVMP/ERA/418282/2005Consultation, London, 2006, pp. 1-59.

[5] Errouissi F., Alvinerie M., Galtier P., Kerboeuf D., Lumaret J.P., The negative effects of the residues of ivermectin in cattle dung using a sustained-release bolus on Aphodius constans (Duft.) (Coleoptera: Aphodiidae), Vet. Res. (2001) 32:421-427.

[6] Finney D.J., Probit Analysis, Cambridge University Press, Cambridge, 1971.

[7] Forbes A., Environmental assessments in veterinary parasitology: a balanced perspective, Int. J. Parasitol. (1996) 26:567-569.

[8] Hempel H., Scheffczyk A., Schallnaß H.J., Lumaret J.-P., Alvinerie M., Römbke J., Toxicity of four veterinary parasiticides on larvae of the dung beetle Aphodius constans in the laboratory, Environ. Toxicol. Chem. (in press).

[9] Hennessy D.R., Modifying the formulation or delivery mechanism to increase the activity of anthelmintic compounds, Vet. Parasitol. (1997) 72:367-382. 
[10] Herd R., Endectocidal drugs: ecological risks and counter-measures, Int. J. Parasitol. (1995) 25:875-885.

[11] ISO (International Organization for Standardization), Soil Quality Determination of dry matter and water content on a mass basis - Gravimetric method, ISO 11465, Genève, Switzerland, 1993.

[12] ISO (International Organization for Standardization), Soil Quality Determination of pH, ISO 10390, Genève, Switzerland, 1994.

[13] Laffont C.M., Bousquet-Melou A., Bralet D., Alvinerie M., Fink-Gremmels J., Toutain P.L., A pharmacokinetic model to document the actual disposition of topical ivermectin in cattle, Vet. Res. (2003) 34:445-460.

[14] Long C., Minutes of the inaugural meeting to discuss development of dung beetle and dung fly laboratory methodologies for veterinary medicinal products, Huntingdon Life Sciences, Huntingdon, 2002, pp. 1-37.

[15] Lumaret J.-P., Étude des conditions de ponte et de développement larvaire d'Aphodius (Agrilinus) constans Duft. (Coléoptère Scarabaeidae) dans la nature et au laboratoire, Vie Milieu (1975) 25:267-282.

[16] Lumaret J.-P., Toxicité de certains helminthicides vis-à-vis des insectes coprophages et conséquences sur la disparition des excréments de la surface du sol, Acta Oecol. Oecol. Appl. (1986) 7:313-324.

[17] Lumaret J.-P., Errouissi F., Use of anthelminthics in herbivores and evaluation of risks for the non target fauna of pastures, Vet. Res. (2002) 33:547-562.

[18] Lumaret J.-P., Errouissi F., Galtier P., Alvinerie M., Pour-on formulation of eprinomectin for cattle: fecal elimination profile and effects on the development of the dunginhabiting diptera Neomyia cornicina (L.) (Muscidae), Environ. Toxicol. Chem. (2005) 24:797-801.

[19] Madsen M., Overgaard Nielsen B., Holter P., Pedersen O.C., Brochner Jespersen J., Vagn Jensen K.M., Nansen P., Gronvold J., Treating cattle with ivermectin: effects on the fauna and decomposition of dung pats, J. Appl. Ecol. (1990) 27:1-15.

[20] Magnusson B.M., Keneth A., Roberts M.S., Veterinary drug delivery: potential for skin penetration enhancement, Adv. Drug Deliv. Rev. (2001) 50:205-227.
[21] McCracken D.I., The potential for avermectins to affect wildlife, Vet. Parasitol. (1993) 48:273-280.

[22] OECD (Organisation for Economic CoOperation and Development), Draft guidance document on the validation and international acceptance of new or updated test methods for hazard assessment (3rd version), OECD Environment, Health and Safety Publications, Series on Testing and Assessment No. 34, 2005, pp. 1-94.

[23] OECD (Organisation for Economic CoOperation and Development), Determination of developmental toxicity of a test chemical to dipteran dung flies (Scatophaga stercoraria L. (Scatophagidae) and Musca autumnalis De Geer (Muscidae)), 2006, Paris, France, pp. 1-12.

[24] Ridsdill-Smith T.J., Effects of avermectin residues in cattle dung on dung beetle (Coleoptera: Scarabaeidae) reproduction and survival, Vet. Parasitol. (1993) 48:127-137.

[25] Römbke J., Hempel H., Scheffczyk A., Schallnaß H.-J., Alvinerie M., Lumaret J.-P., Environmental risk assessment of veterinary pharmaceuticals: development of a standard laboratory test with the dung beetle Aphodius constans, Med. Vet. Ent. (in press).

[26] Sommer C., Steffansen B., Overgaard Nielsen J., Gronvold K.M., Vagn Jensen J., Brochner Jespersen J., Springborg Nansen P., Ivermectin excreted in cattle dung after subcutaneous injection or pour-on treatment: concentrations and impact on dung fauna, Bull. Ent. Res. (1992) 82:257-264.

[27] Strong L., Overview: the impact of avermectins on pastureland ecology, Vet. Parasitol. (1993) 48:3-17.

[28] Swift M.J., Heal O.W., Anderson J.M., Decomposition in terrestrial ecosystems, Studies in Ecology, Vol. 5, Blackwell Scientific Publications, Oxford, 1979.

[29] VICH-GL38: Environmental Impact Assessments (EIAs) for Veterinary Medicinal Products - Phase II guidance, CVMP/VICH/790/03, EMEA, London, 2005, pp. 1-38.

[30] Woodward K.N., Veterinary pharmacovigilance. Part 3. Adverse effects of veterinary medical products in animals and on the environment, J. Vet. Pharmacol. Ther. (2005) 28:171-184. 